\title{
Pemodelan Representasi Pengetahuan Berbasis OWL untuk Objek Arsitektur Candi di Indonesia
}

\author{
Thalia Maria Camilo ${ }^{1}$, Gloria Virginia ${ }^{2}$, Budi Susanto ${ }^{3}$, Umi Proboyekti ${ }^{4}$ \\ Teknik Informatika,Universitas Kristen Duta Wacana \\ Jl. Dr. Wahidin Sudiro Husodo No.5 - 25, Yogyakarta \\ thalia.marialti.ukdw.ac.id \\ ${ }^{2}$ virginialstaff.ukdw.ac.id \\ 3budsusestaff.ukdw.ac.id \\ ${ }^{4}$ othielstaff.ukdw.ac.id
}

\begin{abstract}
The temple is an example of cultural heritage. The large number of Indonesian temples makes information spread on the internet very much. But the information is not a single piece of information. Therefore, we need a system that can store this information. To help processing temple data, a semantic web system was created. This system will help model temple data. The purpose of making this system is to model data and display accurate information about temples in Indonesia. The system was built using the On-To-Knowledge method. The semantic web system that was built was based on OWL and the database used was SPARQL. The semantic web system is able to connect temple culture data with other cultures. In addition, the system can also display information in the form of descriptions, images, and visualizations of Indonesian temple data. The information displayed on the Indonesian temple semantic web system does not only come from literature studies, but also uses linked open data (LOD). By using LOD, the system can present information from DBpedia to complete information on the Indonesian temple's semantic web system.
\end{abstract}

Keywords - Candi Indonesia, Semantic Web, On-ToKnowledge, OWL, SPARQL

Intisari-Candi merupakan salah satu contoh warisan budaya. Jumlah candi Indonesia yang banyak membuat informasi yang tersebar di internet juga sangatlah banyak. Namun informasi tersebut bukanlah suatu kesatuan informasi. Oleh karena itu, dibutuhkan sebuah sistem yang dapat menyimpan informasi-informasi tersebut. Untuk membantu pengolahan data candi, maka dibuat sistem semantic web. Sistem ini akan membantu memodelkan data candi. Tujuan dari sistem ini adalah untuk memodelkan data dan menampilkan informasi yang akurat tentang candi yang ada di Indonesia. Sistem dibangun dengan menggunakan metode OnTo-Knowledge. Sistem semantic web yang dibangun berbasis OWL dan database yang digunakan adalah SPARQL. Sistem semantic web mampu menghubungkan data kebudayaan candi dengan kebudayaan yang lain. Selain itu, sistem juga dapat menampilkan informasi berdasarkan deskripsi dan gambar dari candi.

Kata Kunci-Candi Indonesia, Semantic Web, On-ToKnowledge, OWL, SPARQL

\section{Pendahuluan}

Candi merupakan salah satu contoh warisan budaya. Indonesia memiliki banyak sekali candi [1]. Kebanyakan candi yang ada di Indonesia merupakan bangunan kuno peninggalan masa Hindu-Buddha.
Candi di Indonesia tidak semua informasinya telah didokumentasikan dengan baik. Kurangnya infrastruktur membuat informasi objek arsitektur candi sulit untuk dapat didokumentasikan. Sehingga pada penelitian ini akan dibangun sistem yang dapat mendokumentasikan data arsitektur candi.

Pada penelitian ini peneliti diharapkan untuk dapat memodelkan data dan menampilkan informasi yang akurat tentang arsitektur candi menggunakan teknologi semantic web. Penelitian ini menggunakan semantic web agar data yang ada dapat dihubungkan dengan data kebudayaan yang lain. Semantic web akan sangat membantu dalam melakukan pencarian data dengan sangat detail. Semantic web mempermudah dalam penyajian informasi karena semantic web membuat mesin lebih mengerti dengan informasi yang dicari.

Pembuatan semantic web menggunakan metode on-toknowledge. Metode ini digunakan untuk pembuatan ontology dimana dalam ontology itu sendiri akan menjelaskan tentang konsep domain dan hubungannya.

\section{LANDASAN TEORI}

\section{A.Semantic Web}

Semantic web adalah perluasan dari world wide web. Semantic web merupakan suatu kumpulan teknologi yang memungkinkan komputer dapat memahami arti dari suatu informasi berdasar pada metadata, yaitu informasi mengenai isi informasi tersebut [2]. [3] Semantic web terdiri dari informasi terstruktur dan metadata eksplisit. Semantic web juga membuka jalan untuk mengakses informasi lebih cepat dan mampu mencari data semantic [3].

Pemetaan data memungkinkan untuk memodelkan semantic domain secara lebih eksplisit [4]. Pemodelan data digunakan untuk membuat RDF triples atau RDF graph Sistem semantic membutuhkan RDF triples untuk perancangan ontology [5].

Mesin pencarian cerdas berbasis semantic web memungkinkan pengguna menentukan query dan mendapatkan hasil yang lebih baik [6]. Mesin pencarian semantic web dapat melakukan pencarian berupa teks, gambar, video, dan lain sebagainya 


\section{B. Resource Description Framework}

Resource Description Framework (RDF) adalah model standar untuk pertukaran data di web [7]. RDF digunakan untuk memodelkan data yang akan ditampilkan. Model data RDF dibuat dalam ekspresi subjek, predikat, objek atau dapat disingkat SPO. Contoh SPO dapat dilihat pada Tabel 1.

$$
\text { TABEL I. }
$$

CONTOH EKSPRESI SPO SEBUAH DATA

\begin{tabular}{|c|l|l|}
\hline \multicolumn{1}{|c|}{ Subjek } & \multicolumn{1}{|c|}{ Predikat } & \multicolumn{1}{|c|}{ Objek } \\
\hline Candi Semar & berada di & Dieng \\
\hline
\end{tabular}

\section{C.SPARQL}

SPARQL adalah protocol dan query yang digunakan untuk mengakses informasi dari semantic web [8]. SPARQL dapat digunakan untuk mengambil dan memanipulasi informasi yang tersimpan dalam file RDF. Contoh query SPARQL yang digunakan untuk menampilkan informasi adalah sebagai berikut:

\section{SELECT * WHERE $\{$ ?s ?p ?o $\}$}

Variabel pada query SPARQL dengan tanda "?" adalah suatu node dalam graph RDF dan "SELECT" digunakan untuk mengembalikan suatu tabel dari variabel dan nilai yang dideskripsikan dalam query.

Pada SPARQL juga terdapat PREFIX yang merupakan suatu resource yang dapat digunakan untuk mengakses informasi [9]. PREFIX digunakan untuk menyingkat resource atau dapat disebut URI (Uniform Resource Identifier). Contoh query PREFIX SPARQL adalah sebagai berikut:

PREFIX rdf: < http://www.w3.org/1999/02/22-rdf-syntaxns\#>

PREFIX rdfs: <http://www.w3.org/2000/01/rdf-

schema\#>

\section{Ontology Web Language}

Ontology Web Language (OWL) merupakan suatu bahasa ontology yang digunakan untuk menjelaskan kelas, properti dan relasi antar objek [10]. OWL terdiri atas tiga sub bahasa yaitu:

1. OWL lite yaitu penggunaan OWL yang didasarkan pada klasifikasi atau batasan tertentu.

2. OWL DL yaitu penggunaan ekspresi dengan perhitungan untuk batasan tertentu.

3. OWL full yaitu penggunaan ekspresi tanpa mengunakan perhitungan

\section{E. Ontology}

Ontology adalah sebuah model yang digunakan untuk membuat konsep abstrak yang dapat dimengerti oleh sebuah mesin. Ontology digunakan untuk menentukan kelas, entitas, dan properti dari sebuah data. Model ontology dapat mendeskripsikan informasi secara sistematis sehingga dapat membantu user dalam melakukan pencarian [9]. Dalam merepresentasikan ontology pada sebuah sistem semantic, dibutuhkan RDF (Resource Description Framework) atau OWL (Web Ontology Language).

Ontology dapat direpresentasikan dalam bentuk relasi, kelas dan contoh [11]. Ontology pada umumnya dapat dibedakan berdasarkan tipenya yaitu :

1. Level atas yang mewakili konsep-konsep umum yang dapat diklasifikasi.

2. Domain ontology yang fokus pada domain tertentu yang lebih spesifik.

3. Task ontology akan menjelaskan tentang konsep dasar dari tugas.

4. Ontology level aplikasi lebih fokus pada domain yang lebih spesifik.

\section{F. On-To-Knowledge}

On-To-Knowledge adalah salah satu metode yang dapat digunakan untuk membangun sebuah ontology. [12] Metode On-To-Knowledge terdiri dari lima tahap yaitu:

1. Feasibility study, tahap untuk mengidentifikasi masalah, peluang, dan solusi dari masalah yang dihadapi.

2. Kickoff, tahap untuk memodelkan spesifikasi kebutuhan dan knowledge sistem.

3. Refinement, tahap yang dilakukan untuk menghasilkan graph ontology.

4. Evaluation, analisis dan menguji kelayakan onology terhadap sistem yang akan dibangun.

5. Maintenance, tahap pengembangan dan pemeliharaan aplikasi berbasis ontology.

\section{G.Linked open data}

Linked Data adalah cara untuk berbagi data atau informasi pada semantic web dengan menggunakan URI dan RDF [13]. Linked open data merupakan bagian dari linked data yang data setnya disimpan pada LOD cloud. Data set linked open data disimpan dalam format linked data. Akses data set dapat dilakukan dengan query SPARQL. Data set yang dapat diakses pada LOD cloud adalah data set dengan format RDF [14].

\section{H.Candi}

Candi merupakan bangunan kuno yang menjadi salah satu warisan kebudayaan. Candi memiliki nilai sejarah yang sangat tinggi. Candi menampilkan pesan tersendiri dari simbol-simbolnya [1]. Pada umumnya candi di Indonesia merupakan peninggalan Hindu-Buddha dan dibangun sebagai tempat ibadah, tempat pemakaman dan tempat penyimpanan.

Candi Hindu-Buddha memiliki hiasan seperti relief. Selain relief, candi Hindu-Buddha juga memiliki hiasan lain yang membedakan keduanya. Pada candi Hindu terdapat hiasan lain berupa arca, sedangkan pada candi Buddha terdapat hiasan berupa arca dan stupa.

\section{Metodologi Penelitian}

\section{A.Tahapan Pembangunan Sistem}

Berikut tahap - tahap pembangunan sistem:

1. Feasibility Study 
Tahap feasibility study merupakan tahap yang dilakukan untuk mempelajari tentang arsitektur candi, semantic web, RDF, OWL, ontology, on-toknowledge dan SPARQL. Dari sumber-sumber yang telah dipelajari, kemudian peneliti merumuskan masalah yang ditemukan, mendefinisikan tujuan dan manfaat dari penelitian.

\section{Kickoff}

Tahap ini menjelaskan tentang model spesifikasi kebutuhan yang dibutuhkan dalam penelitian. Spesifikasi yang dibutuhkan adalah sebagai berikut:

a. Kebutuhan fungsional

Pada penelitian ini, sistem diharapkan mampu menjalankan fungsi-fungsi berikut :

- Sistem dapat mengambil dan menampilkan objek candi dan relasinya dari database.

- Sistem dapat menampilkan visualisasi data objek candi dan relasinya dalam bentuk graf.

- Sistem dapat melakukan pencarian sesuai dengan kata kunci dari pengguna.

b. Kebutuhan perangkat

Spesifikasi kebutuhan perangkat yang mendukung penelitian adalah sebagai berikut:

- Kebutuhan perangkat keras

Spesifikasi perangkat keras yang digunakan adalah monitor 14" dengan resolusi 1280 x 800 pixel, processor Intel(R) Core(TM) i5-8250U dengan kecepatan $1.80 \mathrm{GHz}$, RAM $8 \mathrm{~Gb}$, harddisk $500 \mathrm{~Gb}$, mouse, keyboard, printer.

- Kebutuhan perangkat lunak Sistem operasi yang digunakan adalah Windows 10. Perangkat lunak yang digunakan adalah Protege 5.5.0, Visual Studio Code, Apache Jena Fuseki 3.10.0, Google Chrome, dan Microsoft Office.

\section{Refinement}

Pemodelan data dan pembangunan sistem candi Indonesia dilakukan dengan beberapa tahap yaitu :

a. Mengumpulkan fakta candi Indonesia

Data-data candi Indonesia dikumpulkan mengacu pada beberapa sumber buku. Buku-buku tersebut yaitu Indonesia Heritage Sejarah Awal [15], Atlas Budaya Indonesia (Edisi Candi)[16], Relief Dan Arca Candi Singosari-Jawi [17], Candi Indonesia Seri Jawa [18].

b. Pemodelan fakta candi dalam bentuk SPO Dari daftar fakta yang telah dikumpulkan kemudian diubah ke dalam bentuk ekspresi subjek, predikat, objek (SPO). Daftar ekspresi SPO digunakan untuk pembentukan class. Penentuan class berdasarkan pada setiap subjek dan objek yang memilki properti.

c. Pemodelan fakta candi dalam bentuk description logics

Selain diubah ke dalam bentuk ekspresi SPO, fakta-fakta tesebut juga dimodelkan lagi menjadi description logics agar fakta-fakta tersebut dapat lebih mudah dimengerti oleh sistem.

d. TBox candi Indonesia

TBox merupakan graph sederhana yang dibuat untuk mendeskripsikan kelas, entitas, dan properti dari data yang telah dikumpulkan. Pada TBox ontology arsitektur candi terdapat beberapa kelas yaitu candi, candi keagamaan, candi Hindu, candi Buddha, candi Siwa Buddha, candi nonkeagamaan, ukuran dan hierarki, candi kerajaan, candi pribadi, candi wanua atau watak, fungsi candi, candi gerbang, candi pedharmaan, candi pemujaan, candi petirtaan, candi stupa, candi wihara, bagian candi, atap candi, badan candi, kaki candi, bahan, daerah, provinsi, karya seni, patung, relief, arca, arca buddha, arca dewa, arca Trimurti, arca dewi, arca makhluk mitos, arca lain, relief cerita, relief tokoh, relief lain, agama, peripih, dan upacara.

e. Ontology candi Indonesia

Pada penelitian ini, data candi Indonesia yang diperoleh dimodelkan dengan mengunakan tools Protege. Model data atau ontology yang dihasilkan akan diterapkan dalam semantic web berbasis OWL.

\section{Evaluation}

Pengujian sistem pada penelitian ini dilakukan dengan validasi ontology mengunakan fasilitas reasoner (HermiT) di Protege. Untuk pengujian pengetahuan ontology dilakukan dengan menggunakan DL query.

\section{B. Use Case}

Sistem semantic web memiliki tiga aktor yaitu user, pemilik informasi, dan admin. User hanya dapat mengakses fungsi pencarian. Pemilik informasi adalah aktor yang memiliki informasi untuk pembuatan sistem semantic web. Informasi yang didapat akan direpresentasikan ke dalam bentuk HTML. Pemilik informasi dapat menambahkan informasi dan dapat mengupdate informasi yang ada pada sistem. Admin adalah aktor yang membuat sistem semantic web. Usecase sistem dapat dilihat pada Gambar 1.

\section{C.Blok Diagram Sistem}

Kejelasan aplikasi arsitektur candi Indonesia yang akan dibangun dapat dilihat pada Gambar 2. Pada bagian tampilan utama disediakan button search yang dapat digunakan untuk mencari informasi tentang kebudayaan Indonesia. Dari keywords yang di-input oleh user, sistem akan menampilkan aplikasi kebudayaan Indonesia sesuai dengan input. Aplikasi menggunakan HTML dan juga javascript sebagai browser. Query SPARQL yang ada pada javascript akan melakukan request ke database SPARQL Endpoint dan informasi yang akan dikembalikan dalam bentuk HTML. Informasi tersebut yang kemudian akan ditampilkan kepada user. 


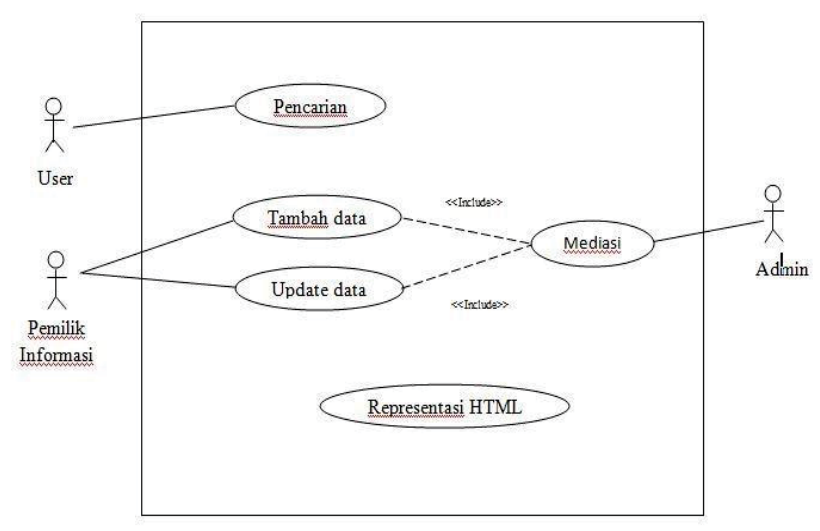

Gambar 1. Use case sistem semantic web

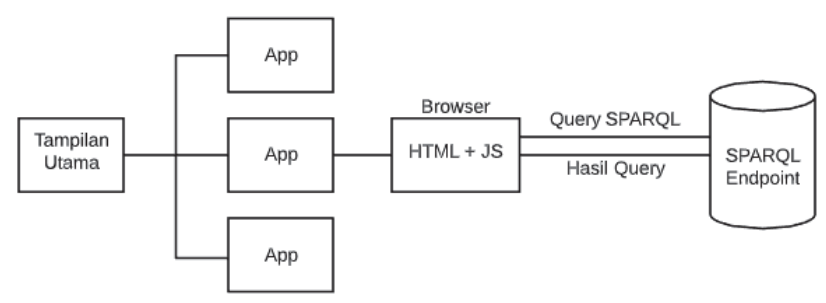

Gamber 2. Blok diagram sistem aplikasi arsitektur candi Indonesia

\section{HASIL DAN ANALISIS}

\section{A.Implementasi Sistem}

Pada tahap implementasi sistem informasi yang ditampilkan oleh sistem tidak hanya dihasilkan dari studi literatur, tetapi juga didapat dari linked open data DBpedia. Informasi yang akan ditampilkan pada sistem yaitu gambar, deskripsi, dan visualisasi.

\section{Model Data}

Pemodelan data objek candi Indonesia dilakukan dengan beberapa tahap yaitu :

a. Mengumpulkan fakta candi Indonesia

Pemodelan data ontology dimulai dengan mengumpulkan fakta-fakta dari beberapa buku penunjang. Beberapa fakta yang telah dikumpulkan dapat dilihat pada Tabel 2.

TABLE II.

DAFTAR FAKTA CANDI INDONESIA

\begin{tabular}{|c|l|}
\hline No & \multicolumn{1}{|c|}{ Daftar Fakta } \\
\hline 1 & $\begin{array}{l}\text { Candi Buddha mempunyai Stupa dan } \\
\text { Arca. }\end{array}$ \\
\hline 2 & Candi Hindu mempunyai Arca. \\
\hline 3 & Hiasan Candi yaitu relief dan arca. \\
\hline 4 & $\begin{array}{l}\text { Tiga bagian candi yaitu kaki candi, } \\
\text { badan candi, atap candi. }\end{array}$ \\
\hline
\end{tabular}

b. Pemodelan fakta candi dalam bentuk SPO

Fakta-fakta yang telah dikumpulkan kemudian diubah ke dalam bentuk ekspresi subjek, predikat, objek (SPO). Contoh hasil ekspresi SPO dapat dilihat pada Tabel 3. Dari daftar SPO tersebut, kemudian dibentuk class. Setiap subjek dan objek yang memiliki properti dapat dijadikan sebagai class. Daftar class yang didapat dari ekspresi SPO tersebut adalah class Candi Buddha, class Candi Hindu, class Hiasan Candi, class Bagian Candi, class Stupa, class Arca, class Relief, class Kaki candi, class Badan Candi, dan class Atap Candi.

TABLE III.

DAFTAR SPO FAKTA CANDI INDONESIA

\begin{tabular}{|c|l|l|l|}
\hline No & \multicolumn{1}{|c|}{ Subjek } & \multicolumn{1}{c|}{ Predikat } & \multicolumn{1}{c|}{ Objek } \\
\hline 1 & $\begin{array}{l}\text { Candi } \\
\text { Buddha }\end{array}$ & Mempunyai & Stupa dan Arca \\
\hline 2 & Candi Hindu & Mempunyai & Arca \\
\hline 3 & Hiasan candi & Yaitu & Relief dan arca \\
\hline 4 & $\begin{array}{l}\text { Bagian } \\
\text { candi }\end{array}$ & Yaitu & $\begin{array}{l}\text { Kaki candi, } \\
\text { badan candi, } \\
\text { atap candi }\end{array}$ \\
\hline
\end{tabular}

c. Pemodelan fakta candi dalam bentuk description logics

Dari daftar fakta yang telah diubah ke dalam bentuk ekspresi SPO, fakta-fakta tesebut kemudian dimodelkan lagi menjadi description logics agar fakta-fakta tersebut dapat lebih mudah dimengerti oleh sistem. Daftar description logics dapat dilihat pada Table 4.

Table 4. Daftar description logics fakta candi Indonesia

\begin{tabular}{|c|l|}
\hline No & \multicolumn{1}{|c|}{ Description Logics } \\
\hline 1 & CandiBuddha $\equiv$ mempunyai.Stupa $\Pi$ Arca \\
\hline 2 & CandiHindu $\equiv$ mempunyai.Arca \\
\hline 3 & HiasanCandi $\equiv$ Relief $\Pi$ Arca \\
\hline 4 & $\begin{array}{l}\text { BagianCandi } \equiv \text { KakiCandi } \Pi \text { BadanCandi } \Pi \\
\text { AtapCandi }\end{array}$ \\
\hline
\end{tabular}

d. TBox candi Indonesia

TBox merupakan graph yang dibuat untuk menjelaskan tentang kelas, entitas, dan properti dari data yang telah dikumpulkan. TBox ontology arsitektur candi dapat di lihat pada Gambar 3. Pada TBox ontology arsitektur candi terdapat beberapa kelas yaitu candi, fungsi, bagian candi, bahan, daerah, karya seni, agama, peripih, dan upacara. Pada penelitian ini, data candi Indonesia yang diperoleh dimodelkan dengan mengunakan tools Protege. Model data atau ontology yang dihasilkan akan diterapkan dalam semantic web berbasis OWL.

e. Ontology candi Indonesia

Pemodelan data candi Indonesia mengacu pada beberapa buku yaitu Indonesia Heritage Sejarah Awal [15], Atlas Budaya Indonesia (Edisi Candi)[16], Relief Dan Arca Candi Singosari-Jawi [17], Candi Indonesia Seri Jawa [18]. Ontology candi Indonesia dimodelkan dengan menggunakan tools Protege. Ontology candi Indonesia terdiri dari class, object properties, data properties, dan individual. Hubungan antar class dan hubungan antar individual dihubungkan dengan menggunakan object properties. Data properties digunakan untuk 
menyimpan data literal. Pemodelan data pada Protege adalah sebagai berikut :

- Class

Class candi Indonesia dapat dilihat pada Gambar 4.

- Object Properties

Object properties candi Indonesia dapat diliat pada Gambar 5.

- Data Properties

Data Properties candi Indonesia dapat dilihat pada Gambar 6.

- Individual

Individual candi Indonesia dapat dilihat pada Gambar 7.

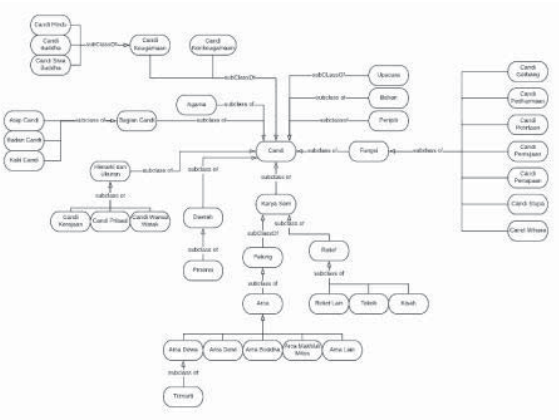

Gambar 3. TBox ontology candi Indonesia

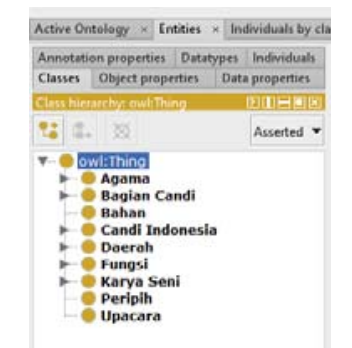

Gambar 4. Class candi Indoneisa

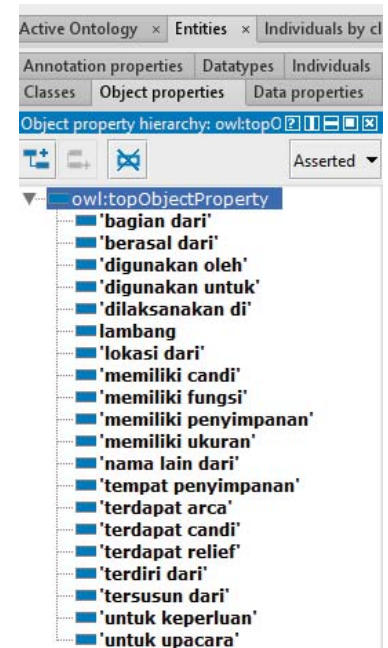

Gambar 5. Object Properties candi Indonesia

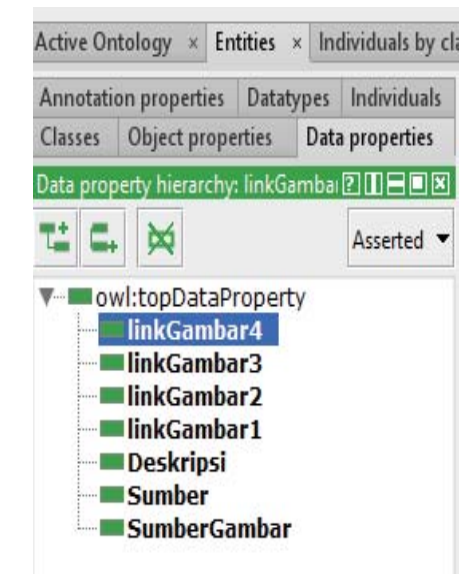

Gambar 6. Data properties candi Indonesia

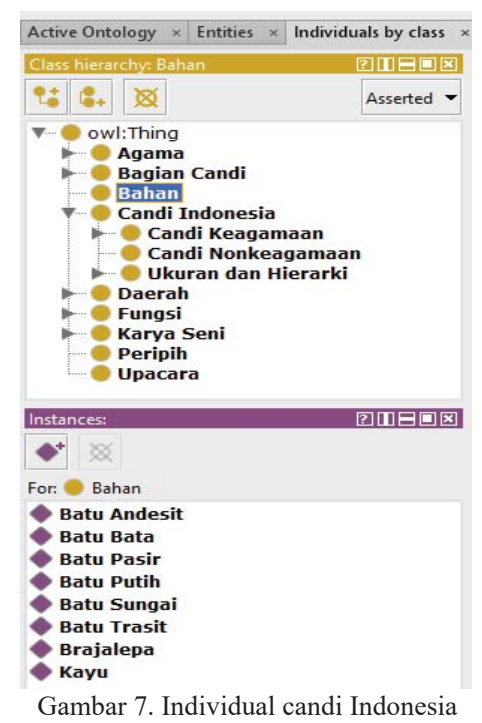

Ontology yang dihasilkan dari Protege disimpan dalam extensi OWL. Ontology kemudian disimpan pada Apache Jena Fuseki. Untuk mengakses data dapat dilakukan dengan query SPARQL. Data tersebut yang kemudian akan ditampikan pada halaman aplikasi web dan juga digunakan untuk pembuatan visualisasi.

2. Penyajian Informasi

Informasi candi Indonesia dapat diakses dengan menggunakan PREFIX berikut:

PREFIX rdfs: < <ttp://www.w3.org/2000/01/rdfschema\#>

PREFIX candi:

$<$ http://alunalun.info/ontology/candi\#>

PREFIX schema: <http://schema.org/>

PREFIX rdf: <http://www.w3.org/1999/02/22-rdfsyntax-ns\#>

PREFIX dbo: < http://dbpedia.org/ontology/>

PREFIX dbpedia-id: < http://id.dbpedia.org/resource>

Untuk menampilakan informasi dibutuhkan query untuk mengakses data pada fuseki server. Contoh query adalah sebagai berikut:

\begin{tabular}{|c|}
\hline SELECT ?idCandi ?candi ?idDaerah \\
?daerah ?gambar \\
WHERE
\end{tabular}




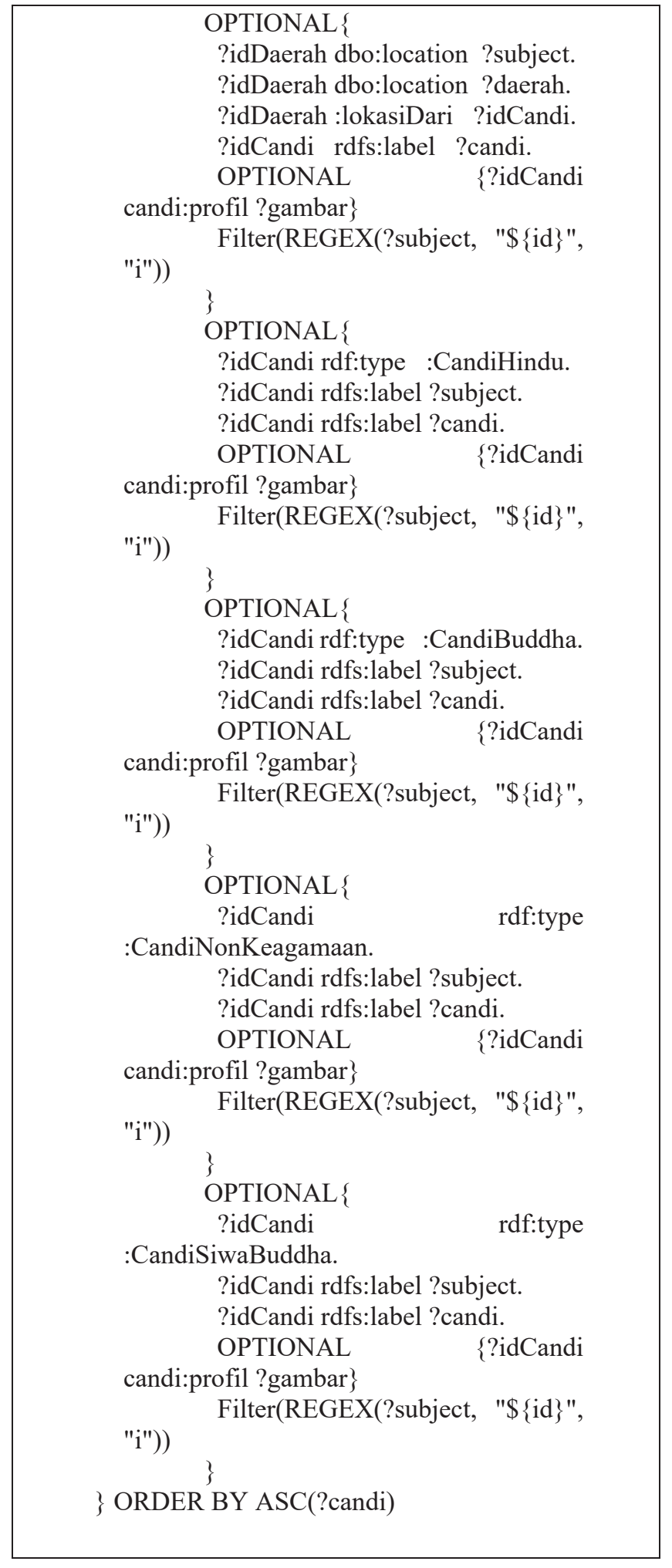

Penyajian informasi pada antarmuka web candi Indonesia adalah sebagai berikut :

\section{a. Haeder}

Pada setiap halaman web candi Indonesia terdapat header yang menyajikan fungsi pencarian. Selain untuk pencarian, header juga berfungsi sebagai button back untuk kembali ke halaman beranda dengan mengklik tulisan candi Indonesia. Header web candi Indonesia dapat dilihat pada Gambar 8.

\section{CANDI INDONESA}

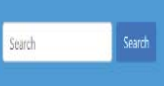

Gambar 8. Header web candi Indonesia

\section{b. Sidebar}

Setiap halaman web memiliki sidebar kecuali halaman visualisasi. Pada sidebar terdapar menu pilihan untuk memilih candi berdasarkan jenisnya, daerah persebaran candi, dan visualisasi. Tampilan sidebar dapat dilihat pada Gambar 9.

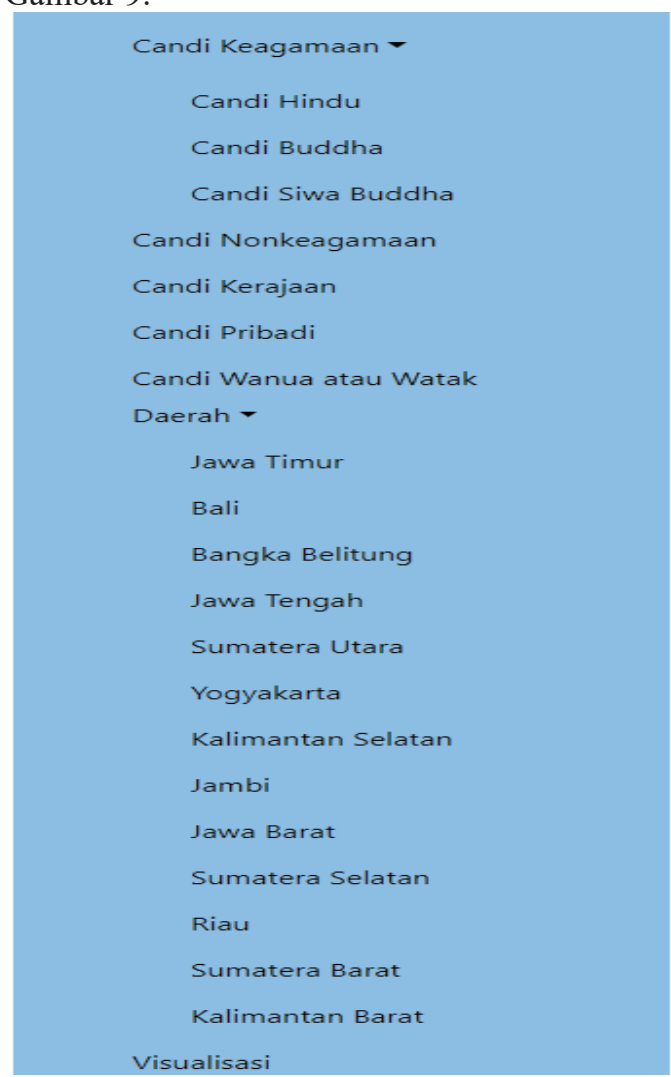

Gambar 9. Sidebar web candi Indonesia

c. Halaman beranda

Halaman beranda dari web candi Indonesia dapat dilihat pada Gambar 10. Halaman ini menyajikan informasi tentang candi Indonesia. Informasi yang dimaksudkan ialah sejarah, struktur bangunan candi, bahan bangunan, jenis candi, dan fungsi candi.

d. Halaman daftar candi

Halaman daftar candi menampilkan candicandi berdasarkan menu yang dipilih pada sidebar. Halaman daftar candi dapat dilihat pada Gambar 11.

e. Halaman detail

Halaman detail menyajikan informasi dari setiap candi. Informasi yang ditampilkan yaitu nama candi, gambar, asal, bahan bangunan, struktur bangunan, jenis candi, nama lain dari candi tersebut, arca, relief, dan upacara yang 
dilaksanakan pada candi. Halaman detail candi dapat dilihat pada Gambar 12.

f. Halaman pencarian

Halaman pencarian adalah halaman yang akan menyajikan daftar candi berdasarkan keyword yang di-input oleh user. Halaman pencarian dapat dilihat pada Gambar 13.

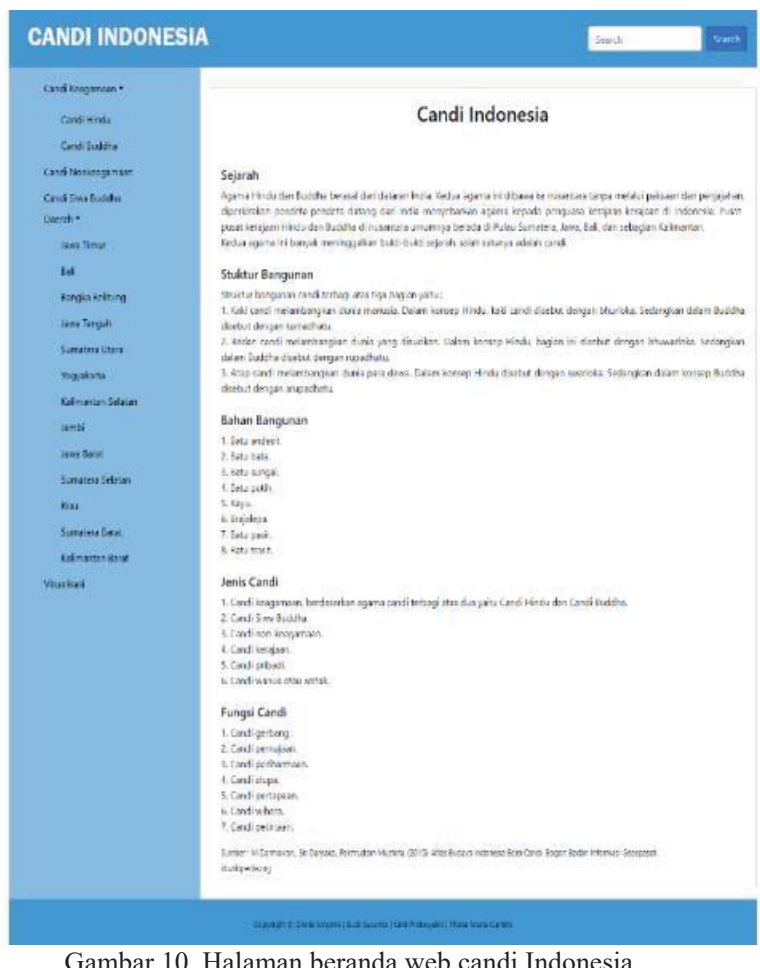

Gambar 10. Halaman beranda web candi Indonesia

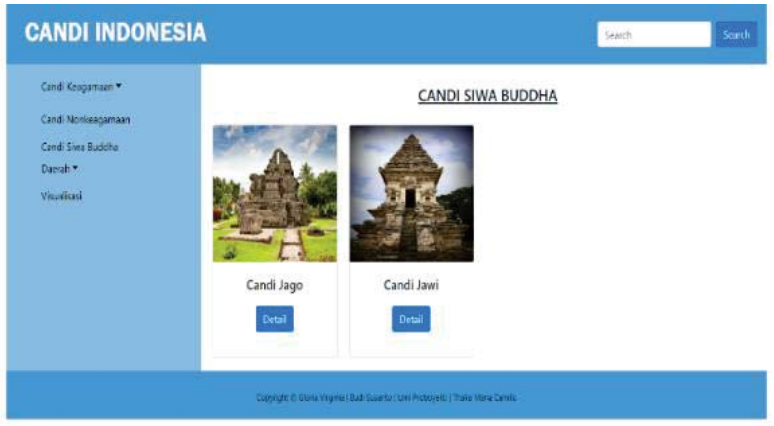

Gambar 11. Halaman daftar candi Indonesia

g. Halaman visualisasi

Halaman visualisasi ialah halaman yang menyasikan visualisasi dari data web candi Indondesia. Halaman visualisasi dapat dilihat pada Gambar 14.

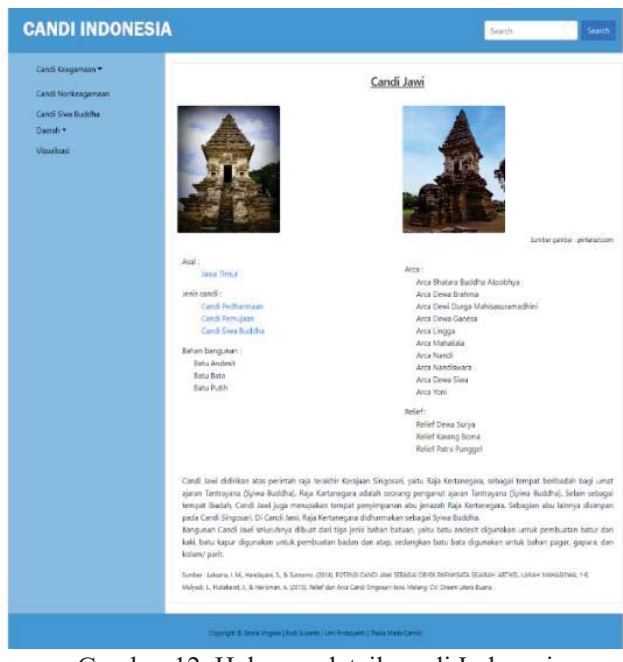

Gambar 12. Halaman detail candi Indonesia

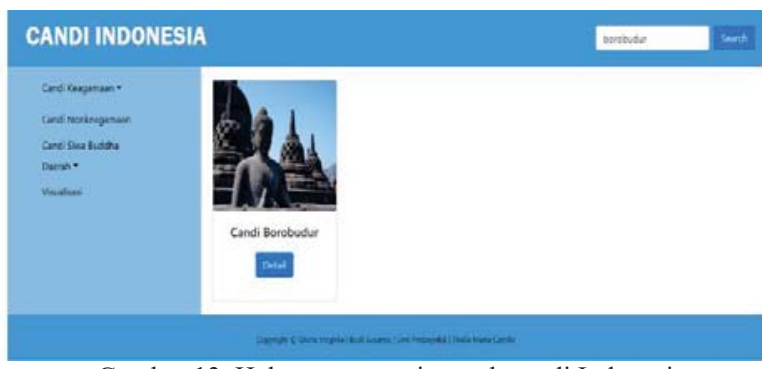

Gambar 13. Halaman pencarian web candi Indonesia

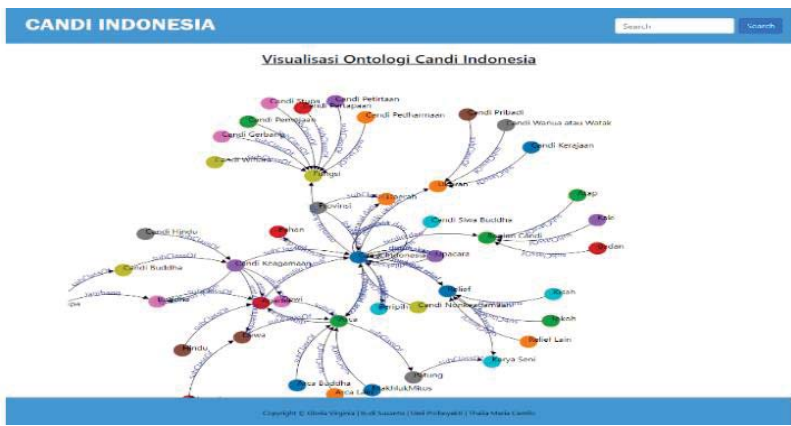

Gambar 14. Halaman visualisasi data web candi Indonesia

\section{B.Pengujian Dan Analisis Sistem}

1. Pengujian Sistem

Pengujian model pengetahuan candi Indonesia dilakukan dengan DL Query yang disediakan Protege dan validasi ontology candi Indonesia dengan menggunakan fasilitas reasoner (HermiT) pada Protege. Contoh hasil DL Query dapat dilihat pada Gambar 16.

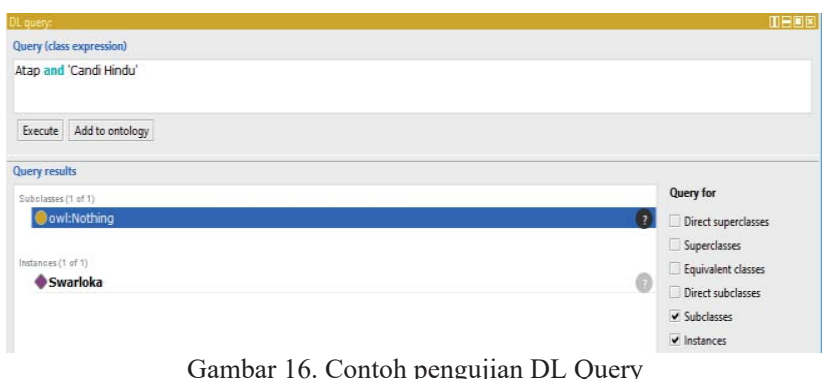

Gambar 16. Contoh pengujian DL Query 


\section{Analisis Sistem}

Pada penelitian pemodelan pengetahuan candi Indonesia yang dilakukan penulis dapat dilakukan analisis berupa:

- Pada tahap feasibility study, penulis mempelajari tentang arsitektur candi, semantic web, RDF, OWL, ontology, on-to-knowledge dan SPARQL. Berdasarkan sumber-sumber yang telah dipelajari, peneliti dapat merumuskan masalah yang ditemukan, mendefinisikan tujuan dan juga manfaat dari penelitian.

- Setelah mengetahui tujuan dari penelitian, peneliti kemudian memodelkan spesifikasi kebutuhan dari penelitian ini. Spesifikasi kebutuhan terbagi atas dua bagian yaitu spesifikasi kebutuhan fungsional dan spesifikasi kebutuhan sistem.

- Representasi pengetahuan candi Indonesia dilakukan dengan menggunakan tools Protege. Data-data yang telah dikumpulkan terbagi atas 44 class, 19 object properties, 11 data properties, dan 480 individual. Untuk setiap class dan individual dihubungkan dengan menggunakan object properties.

- Class candi Hindu, class candi Buddha, dan class candi Siwa Buddha merupakan class yang bersifat disjoin atau tidak memiliki hubungan satu dengan yang lainnya.

- Model data yang dihasilkan disimpan dalam extensi OWL yang kemudian disimpan pada fuseki server. Data tersebut kemudian dapat diakses dengan menggunakan query SPARQL.

- Sistem yang dibangun dapat menampilkan informasi detail tentang candi Indonesia. Informasi yang ditampilkan tidak hanya berasal dari database tetapi juga manggunakan linked open data ke DBpedia.

- Sistem yang dibangun dapat menampilkan visualisasi dari data candi Indonesia.

- Ontology candi Indonesia dinyatakan valid dengan dibuktikan dari hasil pengujian evaluasi konsistensi pengetahuan menggunakan HermiT Reasoner. Validasi ini bertujuan untuk menguji logika dari ontology yang dibangun.

- Ontology candi Indonesia juga diuji dengan menggunakan DL Query. Pengujian ini didasarkan pada fakta-fakta candi Indonesia yang telah dikumpulkan.

- Sistem yang dibangun merupakan sistem aplikasi semantic web berbasis OWL yang dapat menyajikan informasi candi Indonesia.

- Pada penelitian ini, sistem belum dapat menampilkan informasi lengkap tentang arca dan relief.

- Sistem aplikasi semantic web dapat diakses oleh siapa saja dan kapan saja dengan koneksi internet.

\section{Kelebihan Dan Kekurangan Sistem}

1. Kelebihan Sistem

Kelebihan sistem adalah sebagai berikut :

- Sistem dapat menampilkan informasi candi Indonesia secara detail.

- Pencarian data dapat dilakukan dengan menggunakan fungsi pencarian dan juga memilih kategori yang telah disediakan pada daftar menu yang ada di sidebar.

- Beberapa informasi yang ditampilkan berasal dari linked open data ke DBpedia.

2. Kekurangan Sistem

Kekurangan dari sistem adalah sebagai berikut :

- Fungsi pencarian yang disediakan hanya dapat melakukan pencarian informasi berdasarkan nama candi dan daerah candi.

- Sistem belum dapat menyajikan informasi detail dari struktur bangunan, arca, dan relief.

- Sistem tidak memiliki fitur update data, sehingga untuk dapat meng-update data harus dilakukan secara manual pada database.

\section{KESIMPULAN}

Kesimpulan yang dapat diambil dari penelitian ini yaitu:

1. Sistem dapat menyajikan informasi candi Indonesia.

2. Model pengetahuan candi Indonesia ditampilkan dalam aplikasi semantic web berbasis OWL.

\section{UCAPAN TERIMA KASIH}

Dalam penelitian tugas akhir ini, penulis mendapatkan bantuan, saran, bimbingan, dari berbagai pihak. Oleh karena itu, penulis ingin mengucapkan terima kasih pertama kepada Tuhan Yesus Kristus, kemudian kepada dosen pembimbing I dan II, teman-teman, serta pihak pihak lain yang tidak dapat penulis sebutkan satu per satu yang berperan secara langsung maupun tidak langsung. Dalam penelitian ini, penulis menyadari bahwa masih ada kekurangan. Oleh karena itu, penulis sangat mengharapkan adanya kritik dan saran dari pembaca.

\section{DAFTAR PUSTAKA}

[1] Arifin, F. (2015). Representasi Simbol Candi Hindu Dalam Kehidupan Manusia : Kajian Linguistik Antropologis. Jurnal Penelitian Humaniora, Vol. 16, No. 2, 12-20.

[2] Dwiono, A. (2013). Mesin Pencari Cerdas dengan Web Semantik. Jurnal Generic, Vol. 8, No. 1, 209-220.

[3] Hassanzadeh, H., \& Keyvanpour, M. R. (2012). Semantic Web Requirements through Web Mining. International Journal of Computer Theory and Engineering, Vol. 4, No. 4.

[4] Binding, C., Charno, M., Jeffrey, S., May, K., \& Tudhope, D. (2015). Template Based Semantic Integration: From Legacy Archaeological Datasets to Linked Data. International Journal on Semantic Web and Information Systems, Vol 11, No 1.

[5] Sagita, D.N. (2015). Model Data Berbasis Semantic Web Untuk Representasi Pengetahuan Busana pengantin Tradisional Yogyakarta. (Undergraduate thesis, Duta Wacana Christian University, 2015). Retrieved from http://sinta.ukdw.ac.id 
[6] Pawełoszek, I., \& Wieczorkowski, J. (2015). The role of semantics in searching for information. Online Journal of Applied Knowledge Management, Volume 3, Issue 1.

[7] RDF Working Group, "Resource Description Framework (RDF)," W3C Semantic Web, 2502 2014. [Online]. Available: https://www.w3.org/RDF/. [Accessed 1803 2018].

[8] Patriatsa, J.B. (2016). Penerapan Prinsip Sematic Web Pada Representasi Sederhana Arsitektur rumah tradisional diy. (Undergraduate thesis, Duta Wacana Christian University, 2016). Retrieved from http://sinta.ukdw.ac.id

[9] Badron, Y. F., Agus, F., \& Hatta, H. R. (2017). Studi Tentang Pemodelan Ontologi Web Semantik Dan Prospek Penerapan Pada Bibliografi Artikel Jurnal Ilmiah. Prosiding Seminar Ilmu Komputer dan Teknologi Informasi, Vol. 2, No 1, 164-169

[10] Andri. (2013). Implementasi Teknologi Web Semantik Dalam Aplikasi Pencarian Katalog Online Perpustakaan Universitas Bina Darma. Jurnal Imiah MATRIK Vol.15 No.1, 11-20.

[11] Hussain, S. M., Kanakam, P., Suryanarayana, D., Gunnam, S., \& S, S. (2016). Semantic Information Retrieval: An Ontology and RDFbased. International Journal of Computer Applications, Vol 156, No 9.

[12] Sureephong, P., Chakpitak, N., Ouzrout, Y., \& Bouras, A. (2008). An Ontology-based Knowledge Management System for Industry Clusters. Global Design to Gain a Competitive Edge, 333-342.

[13] Khusro, S., Jabeen, F., Mashwani, R. S., \& Alam, I. (2014). Linked Open Data: Towards the Realization of Semantic Web- A Review. Indian Journal of Science and Technology, Vol 6, 745-764.

[14] Hendrik, \& Cahyono, B. A. (2017). Model WordNet Bahasa Indonesia berbasis Linked Data. JNTETI, Vol. 6, No.1, 8-14.

[15] Saputra, K. H. (2002). Indonesia Heritage Sejarah Awal. Buku Antar Bangsa untuk Grolier International.

[16] Atlas Budaya Edisi Candi. (2015). Atlas Budaya Indonesia (Edisi Candi). Bogor: Badan Informasi Geospasial.

[17] Mulyadi, L., Hutabarat, J., \& Harisman, A. (2015). Relief Dan Arca Candi Singosari - Jawi . Malang: CV. Dream Litera Buana.

[18] Sedyawati, E., Santiko, H., Djafar, H., Maulana, R., Ramelan, W. D., \& Ashari, C. (2013). Candi Indonesia Seri Jawa. Direktorat Jenderal Kebudayaan. 